\title{
PRODUÇÃO E QUALIDADE DA VIDEIRA CV. NIÁGARA ROSADA EM DIFERENTES ÉPOCAS DE PODA NO SUDOESTE GOIANO ${ }^{1}$
}

\author{
SOLANGE NEIS ${ }^{2}$, EDÉSIO FIALHO DOS REIS 3 , SILVIA CORREA SANTOS ${ }^{3}$
}

RESUMO - O experimento foi realizado no município de Aparecida do Rio Doce-GO, no sudoeste Goiano, durante os anos de 2007 e 2008, visando a caracterizar a produção da videira 'Niágara Rosada', em diferentes épocas de poda: (1) 09-07-07; (2) 28-09-07; (3) 03-03-08 e (4) 19-04-08. Variáveis associadas à produção por planta, avaliação de cachos e bagas, folhas remanescentes na colheita, posição de brotos na gema e quantidade de cachos/broto, $\mathrm{pH}$, sólidos solúveis (SS), acidez titulável (AT) e relação SS/AT foram analisadas nas produções obtidas nas quatro épocas de poda. A maior massa de cachos foi encontrada nas podas de julho e de abril. As podas realizadas em março e abril permitiram maior número de cachos e maior produtividade. A poda de setembro apresentou maior comprimento, largura e massa de bagas. A qualidade dos frutos foi semelhante entre as safras, mostrando apenas diferenças significativas para $\mathrm{pH}$, AT e para a relação SS/AT nas quatro épocas. A época de poda 3 apresentou o menor valor de folhas remanescentes em relação às demais ( 6,15 folhas), não sendo considerado como grande desfolha nem causando quedas de produtividade. Para a avaliação da posição do broto na gema, a maior média foi observada na época de poda 1 , sendo que as gemas de maior frequência de emissão de ramos com frutos foram aquelas onde se aplicou a cianamida hidrogenada ( $3^{\mathrm{a}}$ a $6^{\mathrm{a}}$ gema), indispensável na estimulação das brotações em videiras. Então, conclui-se que a videira Niágara Rosada pode ser podada nas quatro épocas do ano estudadas no Sudoeste Goiano, já que as avaliações dos cachos e bagas mostraram-se satisfatórias em relação a outras regiões, e as precipitações não afetaram a qualidade final dos frutos em nenhum dos períodos.

Termos para indexação: Vitis labrusca, qualidade da uva, produtividade.

\section{PRODUCTION AND QUALITY OF VIDEIRA CV. NIAGARA ROSADA IN DIFFERENT PRUNING TIMES IN SOUTHWEST GOIÁS}

\begin{abstract}
The experiment was conducted in Aparecida do Rio Doce, Southwest Goiás, during the year 2007 and 2008, to characterize the production of grapevine cv. Niagara Rosada, in different pruning times: (1) $7 / 9 / 07$, , (2) $9 / 28 / 07$, , (3) $3 / 3 / 08$ and (4) 4/19/08. Variables associated to plant production, evaluation of bunches and berries, leaves at harvest, position of fruitful branch in the yolk, number of clusters/fruitful branch, $\mathrm{pH}$, soluble solids, titratable acidity and soluble solids by titratable acidity ratio related to harvests were analyzed. Time of pruning 3 showed the lowest value of leaves at harvest than the others (6.15 leaves) being not considered large or causing defoliation and loss of productivity. For the evaluation of the position of fruitful branch in the yolk, the highest average was observed at the time of pruning 1, where the yolk of higher transmission frequency of branches with fruit were the ones that have been applied hydrogen cyanamide (3rd to 6th yolk), indispensable in the stimulation of the shoots in grapevines. So it follows that the grapevine Niagara Rosada can be pruned in the four seasons studied in Southwest Goiás, since the evaluations of clusters and berries were shown to be satisfactory in relation to other regions and rainfall did not affect the final quality of fruits in any period.
\end{abstract}

Index terms: Vitis labrusca, grape quality, productivity.

\footnotetext{
${ }^{1}$ (Trabalho 264-09). Recebido em: 25-11-2009. Aceito para publicação em: 12-08-2010. Parte da Dissertação de Mestrado da primeira autora.

${ }^{2}$ Mestre, Pós-Graduação em Agronomia - UFG - Câmpus Jataí-GO - Rodovia Br 364, Km 192, n.1800, Setor Parque Industrial. CEP: 75801-615. E-mail: solangeneis@hotmail.com;

3Professor Colaborador e Orientador Adjunto IV - UFG - Câmpus Jataí-GO. E-mails: scscorrea@yahoo.com.br; edesio7@brturbo.com.br.
} 


\section{INTRODUÇÃO}

A produção de uvas no Brasil em 2007 foi de 1.354.960 toneladas. A área plantada passou de 87.550 hectares em 2006 para 89.946 ha em 2007 (incremento de 2,74\%). Houve redução na produção de uvas nos Estados de São Paulo (-1,19\%) e de Minas Gerais (-2,62\%). Entretanto, obteve-se acréscimo da produção no Estado da Bahia, 34,45\%, seguido pelos Estados de Santa Catarina (14,16\%) e do Rio Grande do Sul (13,04\%). Embora não apareça nas estatísticas do IBGE, a viticultura está sendo implementada em vários Estados como Mato Grosso do Sul, Goiás, Espírito Santo e Ceará (EMBRAPA, 2008).

Em meados da década de 1980, houve uma natural exigência de ajustes das características dos produtos ofertados às necessidades do mercado consumidor, e entre as diferentes alternativas possíveis havia um interesse especial pela videira 'Niágara Rosada', tanto pela boa aceitação que tem no mercado consumidor brasileiro, quanto pelo baixo custo de produção e possibilidade de produzir na entressafra das tradicionais regiões produtoras, ou seja, região Sul do Brasil e leste paulista (KUHN, 2003).

A 'Niagara Rosada', que é produzida no período de entressafra, na região de Jales-SP, nos de meses de setembro-outubro, encontra problemas relacionados à dificuldade de emissão e desenvolvimento das brotações após as podas de produção, realizadas quando da ocorrência de temperaturas inferiores a $10^{\circ} \mathrm{C}$, normalmente entre maio e julho. Isto tem provocado redução na produção e desestímulo dos viticultores por esta cultivar (FRACARO et al., 2004).

Em razão da expressão continental do território e da tecnologia disponível, é possível produzir uva para mesa em todos os meses do ano. No Sul do Brasil, a colheita estende-se de dezembro a fevereiro. Nas regiões tradicionais produtoras de São Paulo, as colheitas ocorrem de dezembro a abril. No norte do Paraná, identificam-se duas épocas de colheita: dezembro a janeiro e maio a julho. Na região noroeste paulista, estende-se de junho a novembro (GONÇALVEZ et al., 1996). Normalmente, a época de colheita no noroeste paulista ocorre na entressafra das regiões produtoras tradicionais, quando os preços são mais elevados. A colheita, quando realizada neste período, correspondendo aos meses de setembro-outubro, tem alcançado preços muito vantajosos (FRACARO ; PEREIRA, 2004). As uvas consumidas no Estado de Goiás são originárias sobretudo da região de Jales e Jundiaí-SP, e de algumas cidades do Paraná.

O cultivo da videira 'Niágara Rosada' (Vitis labrusca L.) em regiões tropicais é recente, restringindo-se às áreas com classificação climática $\mathrm{AW}$, aquelas com inverno seco e chuvas máximas de verão. Nessas áreas, tem-se buscado a obtenção de uma safra no período mais seco do ano, sob irrigação, deixando-se o período mais úmido para o ciclo de formação dos ramos, com ou sem obtenção de uma safrinha (CONCEIÇÃO; MAIA, 2007).

A 'Niágara Rosada' tem-se apresentado como uma alternativa interessante para a produção de uvas no sudoeste goiano, pela rusticidade, menor número de tratos culturais e por apresentar baixo custo de produção em relação às uvas finas para mesa. A caracterização da produção é um fator relevante para quantificar a produção final, além de mostrar aos produtores da região o desempenho e a rentabilidade da cultura nas condições locais.

Um dos fatores de maior relevância na produção de uva está relacionado à sua época de poda. A poda é feita durante o período de repouso da videira, isto é, desde a queda das folhas até pouco antes do início da brotação.

A época de poda depende de vários fatores, entre os quais a cultivar, o tamanho do vinhedo, a topografia do terreno (riscos de geadas tardias), a disponibilidade de mão de obra qualificada, a concorrência com outras atividades na propriedade, a umidade do solo e os objetivos da produção (indústria e mesa) (MANDELLI; MIELE, 2007).

Desta forma, o objetivo deste trabalho foi avaliar a produção da videira cv. Niágara Rosada, em quatro épocas de poda, no município de Aparecida do Rio Doce-GO.

\section{MATERIAL E MÉTODOS}

O experimento foi conduzido na Fazenda Campo Belo, localizada no município de Aparecida do Rio Doce-GO. Apresenta as coordenadas geográficas: $18^{\circ} 09^{\prime} 40^{\prime \prime} \mathrm{S}, 51^{\circ} 25^{\prime} 57^{\prime} \mathrm{W}$, e altitude de 590 m. Segundo Mariano e Scopel (2001), o clima da região é $\mathrm{AW}$, apresentando uma temperatura média anual de $22^{\circ} \mathrm{C}$ e índice pluviométrico de $1.650 \mathrm{~mm}$.

Foram utilizadas videiras cv. Niágara Rosada enxertadas sobre o porta-enxerto IAC 572 'Jales', conduzidas no sistema de latada, em espaçamento de 3,0 × 3,0 m, e cultivadas em solo tipo Argissolo. O sistema de irrigação adotado foi o de microasperção subcopa ( 90 emissores, com pressão de $2 \mathrm{~kg}$ e vazão de $50 \mathrm{~L} / \mathrm{h}$ ), e um turno de rega de sete horas a cada três dias sem precipitação.

$\mathrm{O}$ delineamento experimental utilizado foi em blocos casualizados, com quatro tratamentos (correspondendo às épocas de poda) e oito blocos, 
e dentro de cada bloco, cada parcela foi constituída por sete plantas, sendo consideradas três plantas úteis. As podas foram realizadas nas seguintes datas: 0907-2007, 28-09-2007, 03-03-2008 e 19-04-2008, e o sistema utilizado foi de poda longa (seis gemas). Em seguida, foi aplicada sobre as quatro últimas gemas, cianamida hidrogenada na concentração de $7 \%$ do princípio ativo, mediante pincelamento. A partir disto, avaliou-se qual a posição das gemas mais férteis entre as seis gemas deixadas durante a poda, contando-se como a primeira gema aquela mais próxima à base, $\mathrm{e}$ a sexta gema a da parte apical, e qual seria a quantidade de cachos emitidos individualmente pelos ramos frutíferos originados dessas gemas.

1-A época de colheita foi determinada a partir da análise visual, período em que $100 \%$ das bagas atingiram coloração de maturação, e quando os teores de sólidos solúveis nas bagas foram superiores a $16^{\circ}$ Brix. Foram analisadas as seguintes variáveis:

2-Número de folhas remanescentes em cada broto, no momento da colheita. Foram determinadas, também, em que posições estavam as gemas mais férteis, entre as seis deixadas durante a poda, e qual a quantidade de cachos em cada broto originado dessas gemas.

3- A parcela foi formada por três plantas, sendo avaliados dez cachos em cada planta, o que gerou um total de 30 cachos, e a partir destes foram obtidas as variáveis: massa, comprimento e largura de cachos.

4-Número médio de cachos: foi determinada a quantidade média de cachos presentes em cada planta da parcela e uma média para a parcela.

5-Além dos cachos, foram avaliadas nove bagas por planta de cada parcela, sendo três parcelas, o que gerou um total de 27 bagas. A partir daí, foram obtidas as variáveis: massa, comprimento e largura de bagas.

6-Teor de sólidos solúveis (SS) ( ${ }^{\circ}$ Brix): realizado com o auxílio de refratômetro, tendo como amostragem nove bagas por planta de cada parcela.A acidez titulável (AT) foi obtida por titulação com $\mathrm{NaOH} 0,1 \mathrm{~N}$, obtendo-se a porcentagem de ácidos totais no mosto.

7-Relação entre sólidos solúveis e acidez titulável (ratio): foi obtida dos resultados obtidos do teor de sólidos solúveis e de acidez total titulável. A expressão dos resultados foi feita por meio dos valores absolutos encontrados, e potencial hidrogeniônico (pH): com auxílio de peagâmetro digital, introduzido no mosto originado por 6 bagas de cada planta da parcela.

Não foi realizado nenhum tipo de tratamento com thidiazuron (TDZ) e/ou ácido giberélico $\left(\mathrm{AG}^{3}\right)$ ou ethephon neste experimento. Os dados coletados foram submetidos à análise de variância e, em caso de significância, foram analisados pelo teste de Tukey, a 5\% de probabilidade.

\section{RESULTADOS E DISCUSSÃO}

Os dados referentes à avaliação de cachos e produtividade de 'Niágara Rosada', em Aparecida do Rio Doce-GO, estão apresentados na Tabela 2.

A massa média dos cachos foi superior nas épocas de poda 1 e 4 (julho e abril), pois não diferiram estatisticamente entre si, com valores de 206,33 e 228,89 g. Estas épocas contaram com a irrigação suplementar para garantir maior produção, visto que, nos dois meses subsequentes às podas 1 e 4 , as precipitações diminuíram (Tabela 1). Essas podas apresentaram o menor e o segundo maior ciclo de produção, respectivamente (Tabela 2). No entanto, somente a época de poda 4 (abril) foi superior estatisticamente em relação às épocas 2 e 3 (setembro e março).

Em relação à produtividade, as épocas de poda 3 e 4 foram superiores estatisticamente em relação às podas 1 e 2 (Tabela 2 ), correspondendo ao período de safra (março e abril) e entressafra (julho e setembro), o que geralmente ocorre nas regiões tropicais produtoras de uva. A produtividade da época de poda 3 foi 23,31 t.ha $^{-1}$, e da época de poda 4 foi 23,04 t.ha $^{-1}$, enquanto nas épocas de poda $1 \mathrm{e}$ 2 a produtividade foi de apenas 13,51 e 14,40 t.ha-1, respectivamente. Segundo Grangeiro et al. (2002), as condições climáticas, principalmente a temperatura e a luminosidade no momento da diferenciação floral, podem ser os principais responsáveis pelo aumento na massa dos cachos.

Segundo Fracaro (2000), a utilização de ethephon em videira 'Rubi', na região noroeste do Estado de São Paulo, resultou em significativo aumento na intensidade de brotação e na produtividade. Em outro experimento, Fracaro et al. (2004) obtiveram resultados semelhantes com o uso do ethephon na cv. Niágara Rosada em Jales-SP, com aumento do número de cachos e da produtividade, especialmente quando da ocorrência de condições climáticas desfavoráveis, e com satisfatório grau de enfolhamento. Fracaro e Boliani (2004) utilizaram diferentes concentrações do ethephon $(4.500,6.000$ e 7.500 ppm) na videira Rubi, na mesma região, e obtiveram aumento de produção em até $31,38 \%$, na maior concentração.

Os melhores comprimentos de cachos foram para as épocas de poda 1 e $4(13,22$ e 13,15 cm), não diferindo estatisticamente da época de poda 2 $(12,32 \mathrm{~cm})$. Resultados semelhantes foram obtidos 
por Botelho et al. (2004) em Junqueirópolis, na região da Nova Alta Paulista, no que se refere a comprimento e largura de cachos, sendo 13,67 e $13,7 \mathrm{~cm}$ e 8,81 e $8,63 \mathrm{~cm}$, respectivamente, mas estes autores utilizaram thidiazuron a $5 \mathrm{~mL} . \mathrm{L}^{-1} \mathrm{em}$ duas aplicações, e thidiazuron $10 \mathrm{mg} . \mathrm{L}^{-1}$ mais ácido giberélico em três aplicações.

Em relação à largura média de cachos, o comportamento foi semelhante para todas as épocas de poda, apresentando a poda 1 como melhor resultado obtido $(8,66 \mathrm{~cm})$, seguida por 8,50 e 7,87 $\mathrm{cm}$ para épocas de poda $4 \mathrm{e} 3$, respectivamente, com exceção da poda $2(7,79 \mathrm{~cm})$, que diferiu significativamente da poda 1 .

De acordo com Pereira e Fracaro (2004), foi possível verificar que, com a utilização de Ethephon na dose de 9L.ha ${ }^{-1}$, houve uma tendência de aumento no comprimento, largura e massa dos cachos e, consequentemente, na produção da 'Niágara Rosada', na região de Jales-SP.

Além da avaliação realizada nos cachos, é importante considerar-se a avaliação de bagas, como massa, comprimento e largura. Esses dados estão representados na Tabela 3 .

Os melhores resultados para massa, comprimento e largura de bagas foram apresentados pela época de poda 2 , sendo estes, 4,60 g, 2,06 cm e $1,89 \mathrm{~cm}$, respectivamente, com colheita realizada em 06-02-08, mês com alta precipitação (Tabela 1). Provavelmente, a absorção da água das chuvas pela planta provocou aumento nas dimensões da baga.

As épocas de poda 1 e 4 apresentaram comportamento semelhante para as três variáveis de bagas avaliadas, tendo 3,60 e 3,54 g de massa de baga, 1,88 e 1,93 cm de comprimento de baga e 1,73 e $1,75 \mathrm{~cm}$ de largura de baga, respectivamente (Tabela 3). No experimento de Botelho et al. (2004), a testemunha (sem aplicação de regulador vegetal) apresentou resultados semelhantes em relação à massa, comprimento e largura na cv. Niágara Rosada $(3,57 \mathrm{~g}, 1,9 \mathrm{~cm}$ e $1,71 \mathrm{~cm})$, respectivamente, na região da Nova Alta Paulista-SP. Pereira e Fracaro (2004) concluíram que o uso da dose 9 L.ha $^{-1}$ de ethephon proporcionou bagas maiores e com maior peso, comprimento e largura, melhorando o aspecto do cacho na cv. Niágara Rosada, em Jales-SP.

Na Tabela 4, estão representados os dados médios de número de folhas remanescentes na colheita, a posição das gemas mais férteis e o número de cachos por broto originado dessas gemas férteis.

O número médio de folhas remanescentes na colheita foi superior na época de poda 2 , com a média de 7,97 folhas, seguidas pela época 4, com 7,07 folhas, sendo que esta não diferiu estatisticamente da época de poda 1, com a média de 6,65 folhas.

A época de poda 3 apresentou o menor valor de folhas remanescentes em relação às demais $(6,15$ folhas), não sendo considerado como grande desfolha nem causando quedas de produção. Nas épocas de poda 1 e 2 , as folhas não foram prejudicadas pela estação chuvosa (Tabelas 1 e 4). No trabalho realizado por Pedro Jr. et al. (1992), observou-se que, com a diminuição da área foliar pela desfolha artificial de $70 \%$, pode-se ter a queda de produção de até $77 \%$ e o aumento de 20 dias na duração do ciclo. Os mesmos autores concluíram que a redução de $15 \%$ da área foliar não afetou a produção de uvas, aumentando muito pouco a duração do ciclo de Niágara Rosada na Estação Experimental de Jundiaí-SP.

Santos (2006), citado por Roberto et al. (2008), declarou que, na comparação de dois vinhedos contrastantes na abertura do dossel, existe, em favor do vinhedo mais aberto, as seguintes variáveis: menor área foliar (número de folhas), maior superfície foliar ativa (exposta à radiação solar) e maior eficiência nos tratamentos fitossanitários. Considerando inicialmente a superfície foliar, destaca-se que não adianta manter no vinhedo uma grande superfície foliar, se estas estão promovendo autossombreamento e reduzindo a carga de cachos por planta.

Fracaro e Boliani (2001) realizaram tratamento com ethephon nas doses de 4.500, $6.000 \mathrm{e}$ 7.500ppm, 20 dias antes da poda, na cultivar Rubi, no noroeste de São Paulo, e obtiveram os melhores resultados na maior dose de ethephon, com maior porcentagem de desfolhamento. Além disso, houve menor tempo de realização da poda, maior porcentagem de gemas brotadas e, consequentemente, maior produção.

O conhecimento da posição das gemas férteis em cada variedade é uma importante informação para a orientação do tipo de poda a ser empregado no vinhedo, com consequentes aumentos de produtividade. Vieira et al. (2006) afirmaram que a fertilidade de gemas é crescente da base para a parte terminal das varas.

Para a avaliação da posição da gema fértil, a maior média foi observada na época de poda 1 , sendo que esta diferiu estatisticamente das demais, que apresentaram médias inferiores (Tabela 4). Esses valores demonstram que as gemas de maior frequência de emissão de ramos com frutos são aquelas onde foram aplicadas a cianamida hidrogenada $\left(3^{\mathrm{a}}\right.$ a $6^{\mathrm{a}}$ gema), indispensável na estimulação das brotações em videiras. As épocas de poda 1; 3 e 4 não diferiram estatisticamente em relação ao número de cachos/ broto, obtendo-se valores de 1,$78 ; 1,88$ e 1,93. A época de poda 4 diferiu estatisticamente somente da 
época de poda 2.

Na região de Jundiaí-SP, Pires et al. (1999) constataram que a pulverização das gemas da videira Niágara Rosada com cianamida hidrogenada adiantou a brotação das gemas e aumentou a porcentagem de gemas brotadas, o número de cachos e a produtividade por planta. Algumas substâncias químicas são responsáveis pelo sabor, como sólidos solúveis e acidez, e precisam ter seus valores avaliados com a finalidade de caracterizar o fruto como um todo, já que estas mesmas características podem sofrer alterações nas diferentes regiões, devido principalmente às mudanças climáticas.

As características de uma cultivar e a maturidade por ocasião da colheita são fatores críticos que influenciam nos atributos de qualidade dos produtos frescos. A maturidade fisiológica é utilizada para definir o ponto ideal de colheita, sendo o estádio de crescimento e desenvolvimento em que os frutos atingem o nível ideal de maturação, estando então apropriados para consumo in natura (CHITARRA; CHITARRA, 2005).

Para a variável sólidos solúveis ( $\mathrm{SS})\left({ }^{\circ} \mathrm{Brix}\right)$, não houve diferença significativa entre as quatro épocas de poda (Tabela 5). Mesmo com períodos de chuvas durante a colheita, nas épocas 1 e 2 , os teores de sólidos solúveis das frutas colhidas em 06-12-07 e 06-02-08 não apresentaram diferença estatística em relação às épocas de podas 3 e 4 , onde a colheita foi realizada em meses praticamente sem precipitação, mas com irrigação suplementar (12-08-08 e 27-0908) (Tabela 1).
A variação foi de 18,44 a $20,84{ }^{\circ}$ Brix nas quatro épocas de poda para a cv. Niágara Rosada nas condições locais, resultado excelente para esta cultivar em regiões tropicais, já que, segundo Terra et al. (1998), as uvas apresentam características desejáveis de colheita e comercialização acima de $14{ }^{\circ}$ Brix.

Esse comportamento pode ser explicado pela boa insolação ocorrida ao longo dos meses de maturação, nas 4 épocas de poda. $\mathrm{O}$ pH apresentou diferenças significativas entre as épocas de poda do primeiro e segundo semestres, sendo que as épocas 3 e $4\left(1^{\circ}\right.$ semestre $)$ apresentam resultados superiores $(3,66$ e 3,60$)$ às épocas 1 e $2\left(2^{\circ}\right.$ semestre $)(3,45$ e $3,38)$, diferindo estatisticamente. Resultados semelhantes foram encontrados por Botelho et al. (2004) em Junqueirópolis-SP.

A acidez titulável foi maior para as épocas de poda 2; 3 e 4, com valores de 2,26; 2,41 e 2,24, sendo que a época de poda 3 diferiu estatisticamente somente da época de poda 1, com valor de 2,07. A relação SS/AT foi superior na época de poda 1 $(10,33)$, seguido pela poda $4(9,22)$, mas a época de poda 1 diferiu estatisticamente apenas das épocas de poda 2 e 3 . É importante ressaltar que as análises de acidez foram realizadas em frutos sem casca. A ausência da casca diminui a acidez, pois a mesma apresenta altos níveis de ácido málico, dependendo principalmente da variedade e clima. Na região de Jales-SP, Pereira e Fracaro (2004) afirmam que a aplicação de ethephon nas videiras não afetou os teores de sólidos solúveis e a acidez titulável, e o seu uso na dose de 9 L.ha-1, aplicado antes da poda de produção, tende a proporcionar melhor qualidade da uva na cv. Niágara Rosada.

TABELA 1 - Dados climáticos fornecidos pela Estação Meteorológica, localizada no Campus Jataí - UFG, convênio com o $10^{\circ}$ DISME (Distrito Meteorológico) - INMET, 2007-2008.

\begin{tabular}{c|cccc|c|cccc}
\hline \multicolumn{1}{c}{ Ano de 2007 } \\
\hline Mês & T máx & T mín T média & $\begin{array}{c}\text { Precipitação } \\
\text { Total (mm) }\end{array}$ & Mês & T máx & T mín & T média & $\begin{array}{c}\text { Precipitação } \\
\text { Total (mm) }\end{array}$ \\
\hline Jan. & 30,80 & 20,98 & 25,89 & 276,10 & Jan & 29,30 & 20,20 & 24,75 & 303,10 \\
Fev. & 30,80 & 19,90 & 25,35 & 296,40 & Fev & 29,90 & 19,80 & 24,85 & 318,00 \\
Mar. & 31,60 & 18,50 & 25,05 & 152,00 & Mar & 29,90 & 19,40 & 24,65 & 383,80 \\
Abr. & 32,38 & 17,33 & 24,85 & 39,70 & Abr & 29,90 & 18,70 & 24,30 & 243,70 \\
Maio & 29,60 & 13,60 & 21,60 & 69,00 & Mai & 28,10 & 14,20 & 21,15 & 61,70 \\
Jun. & 30,10 & 10,90 & 20,50 & 3,40 & Jun & 28,90 & 13,30 & 21,10 & 2,43 \\
Jul. & 29,10 & 11,20 & 20,15 & 32,00 & Jul & 30,20 & 9,80 & 20,00 & 0,00 \\
Ago. & 32,00 & 12,40 & 22,20 & 0,00 & Ago & 32,90 & 13,10 & 23,00 & 0,60 \\
Set. & 35,00 & 17,20 & 26,10 & 21,40 & Set & 33,30 & 14,70 & 24,00 & 12,30 \\
Out. & 33,70 & 19,20 & 26,45 & 103,60 & Out & 32,60 & 20,00 & 26,30 & 150,00 \\
Nov. & 31,20 & 19,80 & 25,50 & 214,50 & Nov & 31,70 & 19,80 & 25,75 & 193,40 \\
Dez. & 30,90 & 19,80 & 25,35 & 248,10 & Dez & 31,00 & 19,80 & 25,40 & 210,90 \\
\hline
\end{tabular}


TABELA 2 - Variáveis de cachos (massa, comprimento e largura) por planta e produtividade em quatro épocas de poda na videira cv. Niágara Rosada em Aparecida do Rio Doce-GO, 2007-2008.

\begin{tabular}{|c|c|c|c|c|c|c|}
\hline \multirow{2}{*}{$\begin{array}{l}\text { Épocas de } \\
\text { poda }\end{array}$} & \multirow{2}{*}{$\begin{array}{l}\text { Ciclo } \\
\text { (dias) }\end{array}$} & \multicolumn{3}{|c|}{ Variáveis de cachos } & \multirow{2}{*}{$\begin{array}{l}\text { Cachos/ } \\
\text { planta }\end{array}$} & \multirow{2}{*}{$\begin{array}{c}\text { Produtividade } \\
\left(\text { t. } \mathrm{h}^{-1}\right)\end{array}$} \\
\hline & & $\begin{array}{c}\text { Massa } \\
(\mathrm{g})^{*}\end{array}$ & $\begin{array}{c}\text { Comprimento } \\
(\mathrm{cm})\end{array}$ & $\begin{array}{l}\text { Largura } \\
(\mathrm{cm})\end{array}$ & & \\
\hline $1(09-07-2007)$ & 127 & $206,33 \mathrm{ab}$ & $13,22 \mathrm{a}$ & $8,66 \mathrm{a}$ & $59,00 \mathrm{c}$ & $13,51 \mathrm{~b}$ \\
\hline $2(28-09-2007)$ & 130 & $190,95 \quad b$ & $12,32 \mathrm{ab}$ & $7,79 \mathrm{~b}$ & $65,60 \mathrm{bc}$ & $14,40 \mathrm{~b}$ \\
\hline $3(03-03-2008)$ & 163 & $188,42 \quad b$ & $11,66 \quad b$ & $7,87 \mathrm{ab}$ & $112,80 \mathrm{a}$ & $23,31 \mathrm{a}$ \\
\hline 4 (19-04-2008) & 161 & 228,89 a & $13,15 \mathrm{a}$ & $8,50 \mathrm{ab}$ & $87,50 \mathrm{ab}$ & $23,04 \mathrm{a}$ \\
\hline$\overline{\mathrm{CV}(\%)}$ & & 10,70 & 5,44 & 7,40 & 23,00 & 32,10 \\
\hline DMS & & 28,87 & 0,95 & 0,84 & 26,15 & 7,49 \\
\hline
\end{tabular}

*Médias seguidas por mesma letra na coluna não diferem entre si, pelo teste de Tukey, a 5\%.

TABELA 3 - Variáveis de bagas (massa, comprimento e largura) na videira cv. Niágara Rosada em quatro épocas de poda, em Aparecida do Rio Doce-GO, 2007-2008.

\begin{tabular}{lccc}
\hline Épocas de & \multicolumn{3}{c}{ Variáveis de bagas } \\
\cline { 2 - 4 } poda & Massa $(\mathrm{g})^{*}$ & Comprimento $(\mathrm{cm})$ & Largura $(\mathrm{cm})$ \\
\hline $1(09-07-2007)$ & $3,60 \mathrm{~b}$ & $1,88 \mathrm{~b}$ & $1,73 \mathrm{bc}$ \\
$2(28-09-2007)$ & $4,60 \mathrm{a}$ & $2,06 \mathrm{a}$ & $1,89 \mathrm{a}$ \\
$3(03-03-2008)$ & $3,39 \mathrm{c}$ & $1,91 \mathrm{~b}$ & $1,71 \mathrm{c}$ \\
$4(19-04-2008)$ & $3,54 \mathrm{bc}$ & $1,93 \mathrm{~b}$ & $1,75 \mathrm{~b}$ \\
\hline CV (\%) & 3,90 & 2,00 & 1,20 \\
DMS & 0,20 & 0,05 & 0,03 \\
\hline
\end{tabular}

* Médias seguidas por mesma letra na coluna não diferem entre si, pelo teste de Tukey, a 5\%.

TABELA 4 - Dados médios de número de folhas remanescentes na colheita, posição de gemas férteis e quantidade de cachos/broto para a videira cv. Niágara Rosada em Aparecida do Rio DoceGO, 2007-2008.

\begin{tabular}{|c|c|c|c|}
\hline $\begin{array}{l}\text { Épocas de } \\
\text { poda }\end{array}$ & $\begin{array}{l}\mathrm{N}^{\mathrm{o}} \text { de folhas } \\
\text { na colheita* }\end{array}$ & $\begin{array}{l}\text { Posição de } \\
\text { gemas férteis }\end{array}$ & $\begin{array}{c}\mathrm{N}^{o} \text { de cachos / } \\
\text { broto }\end{array}$ \\
\hline $1(09-07-2007)$ & $6,65 \mathrm{bc}$ & $5,89 \mathrm{a}$ & $1,78 \mathrm{ab}$ \\
\hline $2(28-09-2007)$ & $7,97 \mathrm{a}$ & $2,34 \quad \mathrm{c}$ & $1,72 \quad b$ \\
\hline $3(03-03-2008)$ & $6,15 \mathrm{c}$ & $4,62 \mathrm{~b}$ & $1,88 \mathrm{ab}$ \\
\hline $4(19-04-2008)$ & $7,07 \mathrm{~b}$ & $4,32 \mathrm{~b}$ & $1,93 \mathrm{a}$ \\
\hline CV $(\%)$ & 6,50 & 11,50 & 7,80 \\
\hline DMS & 0,63 & 1,68 & 0,21 \\
\hline
\end{tabular}

* Médias seguidas por mesma letra na coluna não diferem entre si, pelo teste de Tukey, a 5\%. 
TABELA 5 - Valores médios de sólidos solúveis (SS), acidez titulável (AT), pH e relação SS/AT em quatro épocas de poda, na videira cv. Niágara Rosada, em Aparecida do Rio Doce-GO, 2007-2008.

\begin{tabular}{l|cccc}
\hline Épocas de poda & Brix (SS) & $\mathrm{pH}$ & AT $(\%)$ & SS/ AT \\
\hline $1(09-07-2007)$ & $20,84 \mathrm{a}$ & $3,46 \mathrm{~b}$ & $2,07 \mathrm{~b}$ & $10,33 \mathrm{a}$ \\
$2(28-09-2007)$ & $18,65 \mathrm{a}$ & $3,38 \mathrm{~b}$ & $2,26 \mathrm{ab}$ & $8,30 \mathrm{bc}$ \\
$3(03-03-2008)$ & $18,44 \mathrm{a}$ & $3,65 \mathrm{a}$ & $2,41 \mathrm{a}$ & $7,71 \mathrm{c}$ \\
$4(19-04-2008)$ & $20,07 \mathrm{a}$ & $3,60 \mathrm{a}$ & $2,24 \mathrm{ab}$ & $9,22 \mathrm{ab}$ \\
\hline CV (\%) & 9,017 & 2,14 & 7,27 & 9,961 \\
DMS & 2,49 & 0,10 & 0,22 & 1,23 \\
\hline
\end{tabular}

* Médias seguidas por mesma letra na coluna não diferem entre si, pelo teste de Tukey, a 5\%.

\section{CONCLUSÕES}

1-A videira Niágara Rosada pode ser podada nas quatro diferentes épocas do ano estudadas no sudoeste Goiano.

2-As precipitações durante a fase final de maturação dos cachos não influenciam na qualidade dos frutos na colheita.

3-Na caracterização qualitativa da uva, observam-se frutos com características organolépticas adequadas, evidenciando, assim, o potencial de produção de uvas de qualidade na região supracitada.

4-A produtividade média é superior nas podas realizadas em março e abril.

\section{REFERÊNCIAS}

ALVARENGA, A. A.; REGINA, M. A.; FRÁGUAS, J. C.; CHALFUN, N. N. J. Influência do portaenxerto sobre o crescimento e produção da cultivar de videira Niágara Rosada (Vitis labrusca L. x Vitis vinifera L.), em condições de solo ácido. Ciência Agrotécnica, Lavras, p.1459-1464, 2002. Edição especial

BOTELHO, R. V.; PIRES, E. J. P.; TERRA, M. $M$. Efeitos de reguladores vegetais na qualidade de uvas 'Niagara Rosada' na região noroeste do Estado de São Paulo. Revista Brasileira de Fruticultura, Jaboticabal, v. 26, n. 1, p. 74-77, 2004.

CHITARrA, M. I. F.; CHITARRA, A. B. Pós-colheita de frutas e hortaliças: fisiologia e manuseio. Lavras : UFLA, 2005. 785p.
CONCEIÇÃO, M. A. F.; e MAIA, J. D. G. Cultivo da videira Niágara Rosada em regiões tropicais do Brasil. Disponível em: $<$ http://sistemasdeproducao. cnptia.embrapa.br/FontesHTML/Uva/UvaNiagaraRosadaRegioesTropicais/clima.htm> Acesso em: 29 ago. 2007.

EMBRAPA UVAE VINHO: EMPRESA BRASILEIRA DE PESQUISAAGROPECUÁRIA. Vitivinicultura Brasileira: panorama 2007. Bento Gonçalves, 2008. Disponível em: $<$ http://www.agrosoft.org. br/?q=node/100154>. Acesso em: 09 jun. 2008.

GIOVANINNI, E. Produção de uvas para vinhos, suco e mesa. Porta Alegre: Renascença, 1999. 364p.

GONÇALVES, J. S. Estrutura de produção e de mercado da uva de mesa brasileira. Agricultura em São Paulo IEA, São Paulo, v.43, n. 1, p. 43-93, 1996.

GRANGEIRO, L. C.; LEÃO, P. C. de; SOARES, J. M. Caracterização fenológica e produtiva da variedade de uva Superior Seedless cultivada no vale do São Francisco. Revista Brasileira de Fruticultura, Jaboticabal, v.24, n.2, p. 552-554, 2002.

KUHN, G. B. Uvas para processamento. Produção: aspectos técnicos. Brasília: Embrapa Informações Tecnológicas, 2003. 134 p.

MANDELLI, F.; MIELE, A. Uvas Americanas e híbridas para processamento em clima temperado. Disponível em: $<\mathrm{http}: / /$ sistemasdeproducao. cnptia.embrapa.br/FontesHTML/Uva/UvaAmericanaHibridaClimaTemperado/poda.htm $>$ Acesso em: 22 ago. 2007. 
MARIANO, Z. de F.; SCOPEL, I. Períodos de deficiências e excedentes hídricos na região de Jataí-GO. In: CONGRESSO BRASILEIRO DE AGROMETEOROLOGIA, 12., 2001, Fortaleza. Anais... Fortaleza: SBA, 2001. p.333-34.

PEDRO JÚNIOR, M. J.; POMMER, C. V.; MARTINS, F. P.; RIBEIRO, I. J. A. Influência da diminuição da área foliar na produtividade e na duração do ciclo da videira 'Niagara Rosada'. Bragantia, Campinas, v. 51, n. 1, p. 57-61, 1992.

PER F. M.; FRACARO, A. A. Efeito do ethephon na qualidade da uva 'Niagara Rosada' (Vitis labrusca L.), produzida na entressafra, na região de Jales-SP. Revista Brasileira de Fruticultura, Jaboticabal, v.26, n.2, p.254-257, 2004.

PIRES, E.J.P.; POMMER, C.V.; TERRA, M.M.; PASSOS, I.R.S. Effects de la cyanamide de calcium et de la cyanamide hydrogéne sur la levée de dormance des bourgeons, le débourrement et le rendement du cépage Niagara Rosé dans la région de Jundiaí, État de São Paulo, Brésil. Bulletin de L'O.I.V., Paris, v.72, n.821-822, p. 457-483, 1999.
ROBERTO, S. R.; PEREIRA, F. M.; BOLIANI, A. C.; SILVA, A. de C. C. da. Origem, botânica e biologia da videira. In: BOLIANI, A. C.; FRACARO, A. A.; CORRÊA, L. de S. Uvas rústicas de mesa: cultivo e processamento em regiões tropicais. Jales: Editora Gráfica Universitária, 2008. 368 p.

SOUZA, P. V. D. de; FOCHESATO, M. L. Emprego da poda verde para a obtenção de duas safras por ciclo vegetativo em 'Niagara Branca'. Bragantia, Campinas, v.66, n.4, p. 611-616, 2007.

TERRA, M. M.; PIRES, E. J. P.; NOGUEIRA, N. A. $M$. Tecnologia para produção de uva 'Itália' na região noroeste do Estado de São Paulo. Campinas: CATI, 1998. 51p. (Documento Técnico, 97).

VIEIRA, C. R. Y. I.; PIRES, E. J. P.; TECCHIO, M. A.; OTSUBO, I. M. N.; VIEIRA, M. C.; YAMASAKI, A. K.; BORTOLANZA, O. Fertilidade de gemas de videiras Niagara Rosada de acordo com o sistema de condução. Revista Brasileira de Fruticultura. Jaboticabal, v.28, n.1, p. 136-138, 2006. 